\title{
Effect of Brain-based Learning in Developing Spatial Ability of Ninth Grade Students with Low Achievement in Mathematics
}

\author{
Ahmad Al-Tarawneh \\ Associate Professor, Psychology Department, \\ Faculty of Educational Sciences, Mutah University, \\ Mutah, Jordan \\ Awad Faek Altarawneh \\ Assistant Professor, Department of Teaching and Curriculum, \\ Faculty of Educational Sciences, The Hashemite University, \\ P.O.B. 330127, Zarqa 13133, Jordan \\ Wejdan Kh. Abd Al-Aziz Karaki \\ Associate Professor, Psychology Department, \\ Faculty of Educational Sciences, Mutah University, \\ Mutah, Jordan
}

DOI: https://doi.org/10.36941/jesr-2021-0112

\section{Abstract}

This study aimed to investigate the impact of a brain-based learning training programme on improving the spatial abilities of a sample of ninth grade elementary school students in Karak Province, Jordan. The study approach is quasi-experimental, the research sample consisted of 6o students selected by the intentional method. After being divided into two groups, 30 students were in the control group and 30 students were in the experimental group. To achieve the objectives of the study, a training programme based on brain-based learning was developed. Seven tests which consisted of spatial perception, spatial visualisation, and spatial orientation were used to measure spatial capacity and its components. The results showed that the training programme improved spatial ability and its three components in the experimental group compared to the control group.

Keywords: spatial ability, spatial perception, spatial orientation, spatial visualisation

\section{Introduction}

Learning with a brain-based learning strategy matches the natural way the brain learns, as it improves memory and student learning, as well as contributing to academic success and deeper levels of thinking and learning. Berger (2005) has shown that brain-based learning aims not to create threats or cause fear in the student. It can develop the person's ability to relate the knowledge they possess to the emotions and the environment in which they live (Berger, 2005). Gulpinar (2005) also 
explained that brain-based learning encompasses educational and learning concepts and mechanisms such as competence learning, self-learning, multiple intelligence, collaborative learning, simulation, motor learning, and problem-based learning (Gulpinar, 2005). Furthermore, Jean pointed out that brain-based learning involves designing learning situations based on the principles that the brain works with to achieve meaningful learning (Jean, 2014).

Brain-based learning is based on a number of principles, including the fact that every human being has a unique brain that is capable of learning and acquiring knowledge when the right conditions are created resulting in the stimulation of learning neurons, thus forming the largest increase in the number of nerve connections with other neurons. The brain is able to process more than one task in parallel, and it performs better when biological, cognitive, emotional, and social factors interact with one another (Train, 2003). Brain-based learning also confirms that differences between individuals in learning and thinking patterns are caused by the fact that the brain relies on one hemisphere to receive and process information, and that it can learn better when both hemispheres work together in the processing, storage, and receipt of information. (Jack, 2010)

Brain-based learning plays a role in developing students' ability to visualise, shapes and perceive the relationships between them, and this is an important factor in developing spatial skills (AlKhalidi, 2003). Crowder explained that spatial ability includes the ability to distinguish between similar things, to imagine and mentally process visual objects, and to draw a realistic picture (Crowder, 2018). Spatial ability encompasses space-related abilities which includes a set of dimensions, such as the ability to recognise objects and patterns. In addition, it includes the ability to change objects, and to recover parts with visual experiences (Olkun, 2003). Spatial ability means the ability to think about movements in the field of vision (Posin, 2010). It is also a combination of skills such as being able to visualise objects from different angles, moving objects in the mind, mental rotation, and visualising two- and three-dimensional geometric shapes (Hegarty \& Weller, 2005, Turgut, 2015; Olkun, 2003). Hegarty (2010) has also shown that spatial abilities are an essential aspect of human perception, and they are essentially a process related to interpreting the incoming data visually perceived by the individual, such as images, objects, maps, and shapes as well as scenes of specific situations in the environment in relation to either a system of standard axes to other situations or to individuals themselves (Hegarty, 2010).

Spatial ability is classified into three components, including spatial perception which involves the ability to distinguish shapes according to the location in which they are situated. Carter explained that spatial ability is perceptual cognitive capacity that enables the individual to understand and perceive spatial relationships (Carter, 2010). It also includes mental rotation which involves the ability to rotate shapes mentally, or the ability to form perceptual assessments of shapes in relation to the observed individual in two or three dimensions (Gilford \& Friesen, 1993). Mental rotation guarantees the ability to transform an image or a whole thing by rotating it as a whole in space, while mental transformation only transforms part of the object or image (Contero, Naya, Company, Saorin, \& Contesa, 2005). Thirdly, spatial visualisation ensures the ability to rotate the shape mentally or parts of it and to recognise the new appearance of things that have been modified within a complex shape (Gilford \& Friesen, 1993). Spatial perception is divided into mental rotation and mental shift (Contero, Naya, Company, Saorin, \& Contesa, 2005). The spatial perception component includes moving an object or a component with the mind during a void, while the spatial orientation component ensures the ability to move the view mentally while the object or component remains constant in outer space. (Contero, Naya, Company, Saorin, \& Contesa, 2005). The most important of the spatial ability skills is the ability to visualise the mental rotation of things, the ability to understand how objects appear in different locations, and the ability to visualise how things relate to each other with an understanding of things in three-dimensional space. (Sutton \& Williams, 20o8)

Maier (1996) explained that spatial ability is an abstract concept consisting of five components, namely (1) spatial perception, which is the ability to perceive vertical and horizontal form, (2) spatial visualisation, which is the ability to visualise the movement of solid objects, (3) mental rotation, which is the ability to locate something after rotating it in a certain direction, (4) spatial relationship, 
which is the ability to understand the elements and components of a thing and the relationship between one element and another, and (5) spatial orientation, which is the ability to maintain the orientation of our bodies mentally and physically in relation to the environment around us.

Several studies dealing with spatial ability have been conducted including the study (Yani \& Rosma, 2020) to assess the extent of spatial ability improvement in the engineering unit of eighth grade students using Macro Media Flash in Indonesia. A quasi-experimental design and a pre- and post-test group was used. The sample consisted of eighth grade students. The results showed that the spatial ability of the students in the engineering unit improved. The rate of improvement was found to be by $61.1 \%$ in spatial perception, $55.6 \%$ in the mental rotation index, and $66.7 \%$ in the spatial orientation index.

Susilawati and Suryadi, (2020) conducted a study to improve mathematical spatial ability through challenge-based learning among university students at the University of Bandung, Indonesia. The findings of this study indicated that there was a significant improvement in the mathematical spatial abilities of the students in the experimental group who received the challenge-based learning. Also, Putri and Hasratuddin (2019) conducted a study to investigate the effectiveness of learning mathematics based on a realistic mathematics education in the spatial and motivational ability of ninth grade students in Nigeria. The results of the study showed the effectiveness of mathematics learning based on a realistic mathematics education in improvement of the spatial ability, motivation, and positive attitudes of the students. Yildiz and Ozdemir (2018) conducted a study to investigate the effectiveness of a training programme based on engineering software to develop spatial ability among eighth grade students in Turkey. The results showed that there were statistically significant differences between the two groups in favour of the experimental group. Another study was conducted by Lowrie, Logan, Harris, and Hegarty (2018) to examine the impact of a programme based on advanced spatial inference maths exercises on spatial abilities development in Australia. The results of their study showed that the children of the experimental classes exceeded the sample of the control classes in terms of spatial abilities. This study differs from other studies because it looked at how a brain-based learning programme affected spatial abilities improvement in a sample of ninth grade students.

This study came from the observation that some students were weak in spatial ability, high anxiety and stress while teaching spatial ability skills, and were therefore trained in spatial ability through a program based on brain-based learning in order to help them master learning principles that facilitate the understanding of spatial ability skills that were not of concern to students during learning. The research task is specifically determined by the answer to the following hypothesis:

There are no statistically significant differences at the level of significance $(\alpha \leq 0.05)$ between the means of the experimental group and the control group in pre and post application on the dimensions of the spatial ability scale and the overall score attributed to the training programme.

\section{$1.1 \quad$ Purpose of the study}

This study aimed to:

a) Construct a training programme based on brain-based learning to improve spatial ability skills in a sample of ninth grade students.

b) Identify its effect on improving spatial skills in the samples studied.

\section{Method and Procedures}

\subsection{Study Approach}

A quasi-experimental approach was used to test the effect of the independent variable (the training programme based on brain-based learning) on the dependent variable (spatial ability) in a sample of low-performing mathematics students from the ninth grade. 


\subsection{Study Sample}

Study participants were intentionally chosen from ninth grade students who were low achievers in mathematics at the Khalid Bin Al Waleed School (a public school in Southern Mazar, in the Karak Governorate of Jordan). The study sample consisted of 60 male students. They were divided into two groups, the control group consisted of 30 students, the rest 30 were in the experimental group. Spatial ability scales were applied to them before the programme was initiated, and their scores were recorded. Moreover, ethical considerations were taken into account as follows: the consent of the director of Khalid Bin Al Waleed School was obtained to conduct a research study on the school's students. Also, the consent of the participant students' parents was also obtained. In addition, the ethics of scientific research were followed, as the information was handled with complete confidentiality and for the purposes of scientific research only. Participants were allowed to withdraw from the training programme at any time.

\subsection{Equivalence of the experimental and control group}

In order to ascertain parity between the experimental group and the control group, the (T) test for independent samples was applied to the pre-performance of the two groups on the spatial ability scale, and on the dimensions included in the scale separately, as shown in Table 1.

Table 1: (T) Test results for independent samples in the pre-measurement on the measure of spatial ability and its dimensions

\begin{tabular}{|l|l|c|c|c|c|c|c|}
\hline Dimension & Group & number & mean & std & df & t & Sig \\
\hline \multirow{2}{*}{ Spatial orientation } & experimental & 30 & 91.86 & 24.067 & 58 & 0.566 & 0.574 \\
\cline { 2 - 8 } & Control & 30 & 88.05 & 27.937 & & & \\
\hline \multirow{2}{*}{ Spatial visualisation } & experimental & 30 & 27.18 & 9.97 & & 0.171 & 0.865 \\
\cline { 2 - 8 } & control & 30 & 26.75 & 9.65 & & & \\
\hline \multirow{2}{*}{ Spatial orientation } & experimental & 30 & 47.97 & 19.53 & & 0.066 & 0.947 \\
\cline { 2 - 8 } & control & 30 & 47.63 & 19.41 & & & \\
\hline \multirow{2}{*}{ Total spatial abilities } & experimental & 30 & 166.65 & 46.87 & & 0.400 & 0.691 \\
\cline { 2 - 8 } & control & 30 & 161.83 & 46.47 & & & \\
\hline
\end{tabular}

It appears from the results presented in Table 1 that there are no statistical differences at the level $(\alpha \leq 0.05)$ between the mean scores of the members of the experimental and control groups in the premeasurement, where the values of $(t)$ calculated for the whole reached $=0.400$ and the level of its significance is equal to 0.691 , which indicates the existence of an equivalence between the control and experimental groups on the spatial ability scale, and on its component dimensions.

\subsection{Study Tools}

\subsubsection{Spatial ability measurements.}

Seven scales were used to measure spatial ability made up of three components: spatial perception, spatial orientation, and spatial visualisation. The sum of these three components gives a total score on spatial ability. These measures were prepared by Ekstrom, French, and Harman (1976) and translated into Arabic. We used the Arabic copy which was used by Lotfi (2007) because Arabic is the formal language used in Jordan. Each component of spatial ability is measured and the sum of each of these factors taken together indicates spatial ability.

Hence, in order to measure spatial perception, perceptual speed, its sub-factor was measured which is the speed of recognising shapes and symbols through the following measures: 
The number comparison test: this consists of 96 items and lasts three minutes. The test requires participants to recognise the similarity or difference between two numbers in the opposite directions. The student's score on this test is extracted by subtracting the incorrect answers from the correct ones and ranges from 96 to -96 . This test is useful for measuring perceptual speed, and is suitable for students from the sixth grade through to the end of undergraduate level.

Identical pictures test: this consists of 96 items divided into two parts and requires each image on the right side to match the image on the left side. The time required to answer each section of this test is 90 seconds, and the score is calculated by subtracting a quarter of the wrong answers from the correct answers. Therefore, the lowest score on this test is -24 while the highest score is 96 .

Hidden shapes test: this consists of 32 items divided into two parts, and in this test the student is asked to search for one of the complex geometric shapes at the top of the page and the following symbols are given to it: A, B, C, D, and E in a complex geometrical form. Six minutes is allocated to answer each part of the test, and the score for this test is calculated by subtracting a quarter of the wrong answers from the correct ones, so the score ranges from -8 to 32 . In addition, spatial visualisation is measured through the following scales

Paper folding test: this consists of 20 items divided into two identical parts, and each of them must be completed within 3 minutes. Each item of this test consists of one line, on the left of the line there are one folded paper ,two or more which have been punched, while on the right line there are five drawings of papers which have been folded, punched and reopened ., the process of folding a sheet or two or more that has been punched present, while on the right line there five drawings of sheets that have been previously folded and punched in different ways and have been reopened, then the student is asked to specify which of these five sheets represent the paper on the left of the line after opening it. The score for this test is calculated by subtracting the correct answers out of the wrong ones divided by four. And, the range is between -5 up to 20 . This test is applicable for the ninth grade until the end of undergraduate level.

Surface development test: this test consists of 12 items, divided into two parts, six minutes are allocated to answer both sections. Each item of the test consists of a drawing of a cropped sheet of paper, the edges of which are coloured and numbered in the places that need to be folded to form a shape which is drawn in the item and each edge of it given an alphabet. Also, in the paragraph with alphabet edges. The student is asked to determine the letters that make up the edges of the shape which resulted from the folding of the edges of the cropped piece, which holds the numbers from 1 to 5. The student's score is calculated by subtracting the correct answers out of a quarter wrong ones, and the range of marks varies from -15 to 60 . The test is valid for students from the ninth grade to the end of undergraduate level.

Spatial orientation is also measured by the sum of students' grades on the following two tests.

Card rotation test: this consists of 20 items, divided into two parts, and the student is required to specify the eight cards on the right of the line, and if they are inverted or rotated in comparison with the ones on the left of the line. Three minutes have been set to answer each of the two parts; the score is calculated by subtracting the wrong answers from the correct answers, and thus the grades range from 160 to 160 . The test is suitable for students from the eighth grade to the end of undergraduate level.

Cube comparison test: this consists of 42 items divided into two parts, and the student is asked to determine if each of the two cubes that each of its items make up represent a rotation of the other. Three minutes are allocated to answer each of the two parts of the test, and the marks are calculated by subtracting the incorrect answers from correct one, so the mark range from -42 to 42 .

Finally, the level of spatial ability is calculated through the sum of its components, which are spatial perception, spatial visualisation, and spatial orientation.

\subsubsection{The validity of spatial ability measures}

The apparent validity of spatial ability measurements was confirmed by presenting them to a group of educational psychologists, by measurement and evaluation, and by mathematics teaching methods in 
Jordanian universities. They demonstrated their suitability for application to subjects of the study sample.

\subsubsection{The reliability of spatial ability measures}

The reliability factor was extracted for the spatial ability measures by applying it to a sample of 30 students from outside the study sample, and it was reported as follows for each scale: the number comparison test (0.76), the identical picture test (o.80), the hidden shapes test $(0.78)$, the paper folding test (0.91), the surface development test (0.94), the card rotation test (o.88), and the cube comparison test (o.82).

\subsection{Training programme}

The programme (index A) started on 10 October 2019 and ended on 5 January 2020, at a rate of two sessions per week. The duration of each session was 45 minutes, which is the length of a school lesson in Jordan.

\section{Results}

To test the validity of this hypothesis, the researchers used the accompanying one-way analysis of variance (ANCOVA) to compare the performance level of each subject on the spatial ability scale and their dimensions in the post-application period according to the group variable (control, experimental). Tables 4 and 5 explain the results.

Table 4: Arithmetic means and standard deviations of the performance level of members of the two groups (control, experimental) in the post application period of the spatial ability scale and its dimensions

\begin{tabular}{|l|l|l|c|c|c|c|c|}
\hline \multirow{2}{*}{ Dimension } & \multirow{2}{*}{ group } & \multicolumn{2}{|c|}{ pre } & \multicolumn{2}{|c|}{ Post } & \\
\cline { 2 - 8 } & & mean & Std. Deviation & mean & Std. Deviation & Estimated Marginal Means & Std \\
\hline \multirow{2}{*}{ Spatial perception } & experimental & 91.86 & 24.07 & 127.05 & 21.45 & 125.93 & 3.48 \\
\cline { 2 - 8 } & control & 88.05 & 27.94 & 87.84 & 26.84 & 88.96 & 3.47 \\
\hline \multirow{2}{*}{ Spatial visualisation } & experimental & 27.18 & 9.97 & 36.87 & 8.96 & 36.77 & 1.499 \\
\cline { 2 - 8 } & control & 26.75 & 9.65 & 27.45 & 9.60 & 27.55 & 1.499 \\
\hline \multirow{2}{*}{ Spatial orientation } & experimental & 47.97 & 19.53 & 69.77 & 20.23 & 69.67 & 2.835 \\
\cline { 2 - 8 } & control & 47.63 & 19.41 & 47.80 & 17.91 & 47.89 & 2.835 \\
\hline \multirow{2}{*}{ Total spatial ability } & experimental & 166.65 & 46.87 & 233.59 & 30.94 & 232.41 & 5.740 \\
\cline { 2 - 8 } & control & 161.83 & 46.47 & 163.43 & 45.19 & 164.61 & 5.740 \\
\hline
\end{tabular}

Table 5: One-way analysis of variance (ANCOVA) to examine the differences between the two groups (control, experimental) in the dimensional application of the spatial ability scale.

\begin{tabular}{|l|l|c|c|c|c|c|c|}
\hline Dimension & Source & Type III Sum of Squares & df & Mean Square & f & sig & Partial Eta Squared \\
\hline Spatial perception & pre & 13633.447 & 1 & 13633.447 & 37.72 & .000 & \\
\hline & group & 20388.100 & 1 & 20388.100 & 56.41 & .000 & .497 \\
\hline & Error & 20600.413 & 57 & 361.411 & & & \\
\hline & Total & 749969.688 & 60 & & & & \\
\hline & Corrected Total & 57293.261 & 59 & & & & \\
\hline Spatial visualisation & pre & 1161.447 & 1 & 1161.447 & 17.24 & .000 & \\
\hline & group & 1274.209 & 1 & 1274.209 & 18.92 & .000 & .249 \\
\hline & Error & 3839.695 & 57 & 67.363 & & & \\
\hline & Total & 68380.750 & 60 & & & & \\
\hline
\end{tabular}




\begin{tabular}{|l|l|c|c|c|c|c|c|}
\hline Dimension & Source & Type III Sum of Squares & $\mathrm{df}$ & Mean Square & $\mathrm{f}$ & sig & Partial Eta Squared \\
\hline Spatial orientation & pre & 7424.400 & 1 & 7424.400 & 30.78 & .000 & .341 \\
\hline & group & 7110.413 & 1 & 7110.413 & $\mathbf{2 9 . 4 8}$ & .000 & \\
\hline & Error & 13747.766 & 57 & 241.189 & & & \\
\hline & Total & $\mathbf{2 3 5 7 3 9 . 0 0 0}$ & 60 & & & & \\
\hline & Corrected Total & $\mathbf{2 8 4 1 0 . 1 8 3}$ & 59 & & & & \\
\hline Total spatial ability & pre & 30712.907 & 1 & & & & \\
\hline & group & 68748.127 & 1 & 30712.907 & 31.118 & .000 & .550 \\
\hline & Error & 56258.672 & 57 & 68748.127 & 69.654 & .000 & \\
\hline & Total & $\mathbf{2 5 2 5 1 5 5 . 5 0 0}$ & 60 & 986.994 & & & \\
\hline & Corrected Total & $\mathbf{1 6 0 8 2 1 . 9 9 6}$ & 59 & & & & \\
\hline
\end{tabular}

The data in Table 5 show that there are statistical differences (at the level of $\alpha \leq 0.05$ ) between the mean performance of the control and test groups in the final measurement on the spatial ability scale and their dimensions after control for the preliminary performance, where the calculated value of (F) for the whole was 69.654 With reference to the modified arithmetical means in Table 4, the differences appear to be in favour of the members of the experimental group as well as confirming the magnitude of the calculated effect, which amounted to 0.550 This indicates the influence of the programme in improving the spatial ability of the members of the experimental group. The data in Table 5 also indicated that there are statistical differences (at the level $\alpha \leq 0.05$ ) between the average performance of the control and experimental groups in the post-measurement period on spatial perception, after controlling for the pre-performance, as the calculated value of (q) reached 56,413 When referring to the modified arithmetical averages in Table 4, it appears that the differences are in favour of members of the experimental group, as well as confirming the size of the calculated effect, which amounted to 0.497 This also indicates the influence of the programme's effect on improving the spatial perception ability of the members of the experimental group.

The data presented in Table 5 indicated that there are statistical differences (at the level $\alpha \leq$ o.05) between the mean performance of the control and experimental groups in the postmeasurement period on spatial perception, after controlling for the pre-performance period, where the calculated value of $(\mathrm{F})$ reached 18.916. When referring to the modified arithmetical means in Table 4, it appears that the differences are in favour of members of the experimental group, as well as confirming the size of the calculated effect, which amounted to 0.249 . This also indicates the influence of the programme's effect on improving the spatial perception ability of the members of the experimental group.

It was evident from the data in Table 5 that there are statistical differences (at the level $\alpha \leq 0.05$ ) between the mean performance of the control and experimental groups in the post-measurement period on spatial orientation after controlling for the pre-performance, where the calculated value of (F) reached 29.481. And when referring to the amended arithmetical means in Table 4, it appears that the differences are in favour of the members of the experimental group, and also confirms the size of the calculated effect, which amounted to 0.341. This indicates that the presence of the programme improves the spatial orientation of the members of the experimental group.

\section{Results Discussion}

The results showed that the training programme based on brain-based learning has an effect on the improvement of spatial ability and its components in students, and this can be attributed to brainbased learning. Students are placed in situations where they must understand the topic on their own (Radin, 2009). In addition, organising and presenting content for students in a simplified and diverse way, dividing tasks and relying on geometric shapes, drawings and plans helped to reduce errors that students may make. In addition, feedback, assistance, and support for students gave them the opportunity to improve their scientific abilities and address weaknesses, which led to development 
and an improvement of their spatial ability.

The results of this study can be attributed to what has been pointed out by Pool (1997), namely that the best learning occurs when the facts and skills to be learnt are linked to real life in which the learner lives. In this study, the brain - based learning programme helped students think according to the demands of life situations, to analyse engineering information, and to understand and discuss real-life tasks and activities. Pool (2009) explained that brain-based learning is characterised by continuous and focussed questions that students are asked, and these help students understand the topic under study. In every lesson these questions are asked to students. (1) Remember: what have you done? (2) Understanding: What was important about it? (3) Application: where can I reuse it? (4) Analysis: what have you done? (5) Creativity: what should I do?

We can conclude that the brain training programme helped to activate a standard of thinking, mathematical justifications, and the correct perception of spatial relationships of the shapes with each other, as well as training the students to mentally retain shapes, despite other movements and changes that occur with them, thus helping to develop the students' spatial ability. Cardellichio and Field (1997) showed that brain-based learning strategies stimulate synapses, and these strategies are represented by hypothetical thinking, symmetry, application of different symbol systems, point analysis, task completion, and content analysis. Zull (2011) explained that these strategies stimulate divergent thinking in learners and develop their ability to associate different things and forms with each other, depending on their daily and previous experiences. This process of linking gives meaning to the learning process by creating new and different links to information which the students are exposed to, thus helping them to expand their thinking in different directions.

Pilcher (2012) pointed out that mental processes based on linking processes stimulate the analytical and imaginative ability of the learner. In addition, Shore (2012) suggested that brain-based learning strategies involve segmenting the learning material, then completing an experimental assignment. After a short rest period, the assignment is discussed with an emphasis on encouraging students to discuss what has been learnt with each other, as well as the use of humour in teaching. Also, Evegueni and Mariana (2002) showed that brain-based learning strategies, including the use of art and role-playing, improve attention, working memory, and visual spatial skills. This creates mental and visual visualisations which are both correct and enjoyable at the same time. This helps create a rich learning environment which allows learners to productively interact with activities and tasks, as well as differentiating and comparing important and unimportant information.

\section{Limitations of the Study}

The programme was applied to a tiny low sample of ninth-grade students, just in one school, so the results can't be generalized.

\section{Conclusions}

In conclusion, the training program based on brain-based learning has contributed to the development of spatial abilities of the members of the experimental group.

The current study recommends the following:

- Applying the training programme to different samples of males and females in order to identify the impact of the programme on gender differences, and to apply it also to samples of different ages.

- Including the principles of brain-based learning in mathematics curricula, and train teachers to use these principles when teaching. 


\section{References}

Berger, S. (2005). The developing person: through the life span (6th Ed). New York: Worth Publishers.

Cardellichio, T., \& Field, W. (1997). Seven strategies that encourage neural branching. Educational Leadership, 54, 33-36. https://eric.ed.gov/?id=EJ540877.

Carter, P. (2010). Tes IQ dan Bakat: Menilai Kemampuan, Penalaran Verbal, Numerik dan Spasial Anda. [IQ and talent test: Evaluate your ability, verbal reasoning, numeric, and spatial ability]. Jakarta: PT Indeks

Contero, M., Naya. F., Company, P., Saorin, J. L., \& Contesa, J. (2005). Improving visualization skills in engineering education. IEEE Computer Graphics and Applications, 25(5), 24-31. https://core.ac.uk/download/pdf/61467762.pdf

Crowder, A. (2018). Differences in spatial visualization ability and vividness of spatial imagery between people with and without aphantasia. A dissertation submitted in partial fulfilment of the requirements for the Doctor of Philosophy in Education, Educational Psychology at Virginia Commonwealth University. https://doi.org/10.25772/TT4H-FN13.

Ekstrom, R.B., French, J.W. and Harman, H.H. (1976) Manual for Kit of Factor- Referenced Cognitive Tests. Educational Testing Service, Princeton.

Evegueni, K., \& Mariana, P. (2002). Information and communication technologies in teacher education: A planning guide. United Nations Educational, Scientific and Cultural Organization, https://unesdoc.unesco.org/ark:/48223/pfoooo129533.

Gulpinar, M. (2005). The principles of brain-based learning and constructivist models in education. Educational Sciences: Theory \& Practice, 5(2), 299-306.

Hegarty, M. (2010). Components of spatial intelligence. Learning, Psychology of Learning and Motivation, 52(10), 265-297. https://doi.org/10.1016/Soo79-7421(10)52007-3

Hegarty, M., \& Waller, D. (2005). Individual differences in spatial abilities. In P. Shah \& A. Miyake (Eds.), The Cambridge handbook of visuospatial thinking. Cambridge: Cambridge University Press. https://doi.org/10.1017/CBO9780511610448.005

Jack, C. (2010). Exploring brain-based instructional practices in secondary education classes, A dissertation submitted in partial fulfilment of the requirements for the degree of Doctor of Education in Curriculum and Instruction, Boise State University.

Jean, D. (2014). Brain-based learning: The neurological findings about the human brain that every teacher should know to be effective. Amity Global Business Review, 9, 15-23.

Al-Khalidi, A (2003) The Psychology of Individual Differences and Mental Excellence, Iraq, Baghdad, Wael House for Publishing and Distribution.

Lotfi, Y. (2007). The level of spatial ability and its development pattern among Palestinian students between grades seven, nine and eleven, unpublished Master's thesis, Birzeit University, Palestine.

Lowrie, T., Logan, T., Harris, D., \& Hegarty, M. (2018). The impact of an intervention program on students' spatial reasoning: Student engagement through mathematics enhanced learning activities. Cognitive Research: Principles and Implications, 3(50), 1-10. https://doi.org/10.1186/s41235-018-0147-y

Maier, P. H. (1996): Spatial geometry and spatial ability - How to make solid geometry solid?In: Elmar CohorsFresenborg, K. Reiss, G. Toener \& H.-G. Weigand (Eds.), Selected Papers from the Annual Conference of Didactics of Mathematics 1996, Osnabrueck, p. 63-75.

Olkun, S. (2003). Making connections: Improving spatial abilities with engineering drawing activities. International Journal for Mathematics Teaching and Learning, 3(1), 1-10. https://www.academia.edu/3194065

Pilcher, J. (2012). Growing dendrites and brain-based learning. Neonatal Network, 31(3), 191-4. DOI: 10.1891/07300832.31.3.191.

Pool, C. R. (1997). Brain-based learning and students. Education Digest, 63(3), 10-15.

Posin, 1. (2010). Visual spatial cognition in neurodegenerative disease. Neurocase, 16(6): 466487. 10.1080/135547910037306oo

Putri, S. K., Hasratuddin, E, S. (2019). Development of learning devices based on realistic mathematics education to improve students' spatial ability and motivation. International Electronic Journal of Mathematics Education, 14(2), 393-40o https://doi.org/10.29333/iejme/5729.

Radin, J. (2009). Brain-compatible teaching and learning: Implications for teacher education. Educational Horizons, 88(1), 40-5o. https://www.jstor.org/stable/42923785?seq=1

Shore, R. (2012). Profound levels of learning through brain-based teaching: A tribute to Roland Barth. Educational Forum, 76(1), 129- 136. https://doi.org/10.108o/oo131725.2011.628197 
Susilawati, W., \& Suryadi, D. (2020). The challenge-based learning to students' spatial mathematical ability. Ahmad Dahlan International Conference on Mathematics and Mathematics Education Journal of Physics: Conference Series. 1613, o12039 IOP Publishing, p1-6 doi:10.1088/1742-6596/1613/1/o12039.

Sutton, K., \& Williams, A. (2008). Developing a discipline-based measure of visualization. UniServe Science Proceedings, 115-120. https://openjournals.library.sydney.edu.au/index.php/IISME/article/view/6252.

Turgut, M. (2015). Development of the spatial ability self-report scale (SASRS): Reliability and validity studies. Quality \& Quantity, 49, 1997-2014. DOI 10.1007/s11135-014-0o86-8.

Yani, M., \& Rosma, F. (2020). Improving students' spatial ability by using macromedia Flash on geometry materials. Malikussaleh Journal of Mathematics Learning, 3(1) 18-22. DOI: https://doi.org/10.29103/mjml.v3i1.2401

Yildiz, S. G., Ozdemir, A. S. (2018). The effects of engineering design processes on spatial abilities of middle school students. International Journal of Technology and Design Education, 30, 127-148. https://doi.org/10.1007/s10798-018-9491-y.

Zull, J. E. (2011). From brain to mind: Using neuroscience to guide change in education. Sterling: Stylus Publishing. https://www.goodreads.com/book/show/10845442-from-brain-to-mind.

\section{Appendix A: Training Program}

\begin{tabular}{|c|c|c|}
\hline $\begin{array}{c}\text { NO. } \\
\text { SESSION }\end{array}$ & TITLE OF THE SESSION & STRATIGIES OF IMPLEMENTATION \\
\hline 1 & Engineering constructions. & \multirow{21}{*}{$\begin{array}{l}\text { The following brain-based learning strategies were } \\
\text { used in the implementation of the training } \\
\text { sessions: } \\
\text { Preparation: in terms of giving a general idea of } \\
\text { the topics to be understood and providing the } \\
\text { learner's brain with the necessary connections, } \\
\text { and focusing on making the learning environment } \\
\text { free from threat } \\
\text { Acquisition: It depends on forming neural } \\
\text { connections by relying on linking with previous } \\
\text { experiences, and the most important tools of } \\
\text { acquisition are the sustaining of visual stimuli, } \\
\text { group learning, sustaining of experiences that are } \\
\text { required to be learned everywhere in the } \\
\text { classroom, and role playing. } \\
\text { Detail: It aims to deepen understanding by } \\
\text { integrating students into various classroom } \\
\text { activities. } \\
\text { Memory formation: aims to strengthen learning } \\
\text { and retrieve information by presenting students } \\
\text { with questions in a way that raises motivation. } \\
\text { Functional integration of the spherical } \\
\text { hemispheres: by giving students additional } \\
\text { activities related to the topic to be understood, } \\
\text { and clarifying its relationship with subsequent } \\
\text { topics, to strengthen and develop correct } \\
\text { connections in the brain. } \\
\text { Providing a real learning environment that makes } \\
\text { the learner try new things safely. }\end{array}$} \\
\hline 2 & Creating a column on a straight line. & \\
\hline 3 & Bisection of a straight piece & \\
\hline 4 & Bisection of the corner. & \\
\hline 5 & circle inside a tria & \\
\hline 6 & $\begin{array}{l}\text { rean Theorem and its application in } \\
\text { t triangles. }\end{array}$ & \\
\hline 7 & al models from two-dimensional networks & \\
\hline 8 & Form & \\
\hline 9 & Spati & \\
\hline 10 & The & \\
\hline 11 & $\begin{array}{l}\text { Extrapolation of a formula for calculating the volume and surface } \\
\text { area of a prism based on solving life problems }\end{array}$ & \\
\hline 12 & $\begin{array}{l}\text { Extrapolating the formula for the law of volume and surface area of a } \\
\text { cylinder. }\end{array}$ & \\
\hline 13 & of the law of vol & \\
\hline 14 & apolation of the law of the size and area of the surface of the & \\
\hline 15 & solving on spatial abilities. & \\
\hline 16 & $\begin{array}{l}\text { the law of the pyramid surface and employ the laws to solve life } \\
\text { problems }\end{array}$ & \\
\hline 17 & $\begin{array}{l}\text { Identifying the congruence of geometric shapes from different } \\
\text { directions }\end{array}$ & \\
\hline 18 & Creating and describing geometric shapes & \\
\hline 19 & Solving Problems Using Pentominoes & \\
\hline 20 & $\begin{array}{l}\text { Presentation and clarification of engineering concepts or properties } \\
\text { using pentominoes. }\end{array}$ & \\
\hline 21 & Seven Shapes Puzzles & \\
\hline
\end{tabular}

